\title{
Hybrid Wing Body Configuration Scaling Study
}

\author{
Craig L. Nickol ${ }^{1}$ \\ NASA Langley Research Center, Hampton, VA 23681
}

The Hybrid Wing Body (HWB) configuration is a subsonic transport aircraft concept with the potential to simultaneously reduce fuel burn, noise and emissions compared to conventional concepts. Initial studies focused on very large applications with capacities for up to 800 passengers. More recent studies have focused on the large, twin-aisle class with passenger capacities in the 300-450 range. Efficiently scaling this concept down to the single aisle or smaller size is challenging due to geometric constraints, potentially reducing the desirability of this concept for applications in the 100-200 passenger capacity range or less. In order to quantify this scaling challenge, five advanced conventional (tube-and-wing layout) concepts were developed, along with equivalent (payload/range/technology) HWB concepts, and their fuel burn performance compared. The comparison showed that the HWB concepts have fuel burn advantages over advanced tube-and-wing concepts in the larger payload/range classes (roughly 767-sized and larger). Although noise performance was not quantified in this study, the HWB concept has distinct noise advantages over the conventional tube-and-wing configuration due to the inherent noise shielding features of the HWB. NASA's Environmentally Responsible Aviation (ERA) project will continue to investigate advanced configurations, such as the HWB, due to their potential to simultaneously reduce fuel burn, noise and emissions.

\section{Nomenclature}

$\begin{array}{ll}\text { AC } & =\text { Aerodynamic Center } \\ \text { BWB } & =\text { Blended Wing Body } \\ \text { CG } & =\text { Center of Gravity } \\ \text { EMA } & =\text { Electromechanical Actuators } \\ \text { HLFC } & =\text { Hybrid Laminar Flow Control } \\ \text { HWB } & =\text { Hybrid Wing Body } \\ \text { LSA } & =\text { Large Single Aisle } \\ \text { LTA } & =\text { Large Twin Aisle } \\ \text { MAC } & =\text { Mean Aerodynamic Chord } \\ \text { NLF } & =\text { Natural Laminar Flow } \\ \text { PR } & =\text { Payload (ton) } * \text { Range (nm K) } \\ \text { RJ } & =\text { Regional Jet } \\ \text { STA } & =\text { Small Twin Aisle } \\ \text { TOGW } & =\text { Takeoff Gross Weight } \\ \text { TSFC } & =\text { Thrust Specific Fuel Consumption } \\ \text { TW } & =\text { Tube-and-Wing } \\ \text { T/W } & =\text { Thrust-to-Weight } \\ \text { VL } & =\text { Very Large }\end{array}$

\section{Introduction}

$\mathrm{T}^{\mathrm{s}}$ HE hybrid wing body, or blended wing body (BWB), configuration has been the subject of numerous studies over the past several decades as a potential future subsonic transport and cargo aircraft with the promise of

\footnotetext{
${ }^{1}$ Senior Aerospace Engineer, Aeronautics Systems Analysis Branch, MS 442, AIAA Senior Member
} 
increased aerodynamic efficiency and reduced noise. Liebeck, et. al. ${ }^{1}$, introduced an 800 passenger BWB design in 1994 with a predicted fuel burn advantage over an equivalent technology tube-and-wing (TW) design of $27 \%$. This 800 passenger design was refined, and presented in $1998^{2}$, with the same $27 \%$ estimated fuel burn advantage over an equivalent technology TW concept. The 800 passenger concept utilized an embedded engine, boundary layer-ingesting propulsion system. A second generation design, sized for approximately 450 passengers, was introduced in $2000^{3}$; however, no performance comparison to a TW configuration was provided. This second generation design utilized a lower risk propulsion integration approach with podded engines mounted on pylons keeping the inlets above the boundary layer. In January, 2002, Liebeck provided an update on the second generation design, termed the BWB- $450^{4}$. A performance comparison to the Airbus A380 showed an estimated 32\% advantage in fuel burn per seat, however no comparisons to advanced TW concepts were provided. In addition, the problem of "stretching" the BWB was addressed by showing a family of BWBs with growth accommodated by adding lateral bays to the centerbody, while maintaining commonality for the outer wing sections and the cockpit. Six versions were shown, ranging from 200 to 450 passengers, however, performance estimates were not provided. The BWB family concept was addressed again by Liebeck in $2003^{5}$ with a comparison of efficiency between a family of BWBs and current TWs. The BWBs showed a 20 to $30 \%$ efficiency advantage, and the efficiency increased with increasing payload/range.

This study investigates the question of HWB fuel burn performance as a function of size. Intuitively, since the HWB promises an aerodynamic efficiency benefit compared to a TW, a longer cruise segment will maximize this potential advantage. Shorter cruise segments generally correlate to smaller aircraft, and the efficiency of the HWB as it is scaled down as compared to an equivalent-technology TW is the focus for this study. As illustrated by Liebeck in reference 2, passenger height is discrete and cannot be scaled. For example, an 800 passenger doubledeck BWB design has approximately half the aerodynamic wetted area per passenger compared to a 100 passenger layout. In order to quantitatively investigate this scaling issue, ten new vehicle concepts were developed; five advanced TW aircraft and five equivalent-technology HWBs. Table 1 shows the vehicle sizes and nomenclature utilized for this study. The TW or HWB designation indicates which type of concept, and the numerical designation indicates passenger count.

Table 1. Vehicle Classes and Nomenclature for Study Concepts

\begin{tabular}{|c|c|c|c|c|c|}
\hline Vehicle Size Class & \# Passengers & $\begin{array}{c}\text { Design Range } \\
(\mathrm{nm})\end{array}$ & Cruise Mach & $\begin{array}{c}\text { Advanced } \\
\text { Tube+Wing }\end{array}$ & HWB \\
\hline Regional Jet & 98 & 2400 & 0.78 & TW98 & HWB98 \\
\hline Large Single Aisle & 160 & 2875 & 0.78 & TW160 & HWB160 \\
\hline Small Twin Aisle & 216 & 6600 & 0.80 & TW216 & HWB216 \\
\hline Large Twin Aisle & 301 & 7500 & 0.84 & TW301 & HWB301 \\
\hline Very Large & 400 & 5800 & 0.85 & TW400 & HWB400 \\
\hline
\end{tabular}

\section{Technology Assumptions}

The ERA project has a goal of simultaneously reducing noise (42 db cumulative below the Stage 4 certification level), fuel burn (50\% reduction compared to currently operating aircraft), and emissions (75\% reduction in nitrogen oxide compared to the current standard) ${ }^{6}$. To meet this goal, ERA is supporting the maturation of key technologies to support a 2020 technology readiness level (TRL) of 6 (system or subsystem model or prototype successfully demonstrated in a relevant environment). A set of technologies with the potential to reach TRL=6 in 2020 and to enable an advanced concept to meet the ERA goal was identified and applied to the ten concepts utilized in this study. This section provides a brief description of these technologies and their associated modeling assumptions.

Drag reduction technologies include hybrid laminar flow control, riblets, and variable trailing edge camber. A hybrid laminar flow system was assumed for the wings and tail surfaces of the advanced TW concepts, and for the outer wing sections of the HWB concepts. The system applies suction to the boundary layer along the wing leading edge coupled with a natural laminar flow airfoil design to result in laminar flow over significant portions of the wing. The suction system requires space, weight and power allocations that are a function of the aircraft size and required mass flow to achieve the desired effect. In previous studies, the weight of the suction system was assumed to be equal to that of the aircraft air conditioning system, based on the similarity of the required equipment (i.e., compressors, valves, ducts, etc.). For this study, an estimate was made for the suction system weight and horsepower based on the running length of the system along the leading edge. Weight and horsepower per foot metrics were 
utilized based on a proprietary study by Boeing performed for NASA and the Air Force Research Lab in 2009. The suction system power required was converted into a fuel flow factor and applied throughout the mission. For the advanced TW concepts, the resulting HLFC system weight to air conditioning system weight ratio ranged from 1.3 for the TW98 down to 0.72 for the HWB400. In addition, a $1 \%$ cruise drag penalty was applied to account for the NLF airfoil design, which is less aerodynamically efficient than an optimized non-NLF design. The assumed benefit of the HLFC system was 50\% chord laminar flow for the upper wing surface, and, in the case of the TW concepts, $50 \%$ chord laminar flow on both sides of the horizontal and vertical tails. NLF was assumed for the nacelles, covering $50 \%$ of the nacelle length. For the HWB concepts, NLF on the nacelles was limited to the upper surface only. A Krueger flap system was assumed for both the TW and HWB concepts to protect the leading edge, resulting in no laminar flow benefits for the under surface of the wing.

A trade-study was performed to determine if the HLFC system, given the space, weight, and power requirements, was preferred over a NLF design. The original assumption was that the HLFC system added value only on the larger-sized aircraft, however, the trade study results showed that the HLFC system was the preferred concept for all vehicle classes, even the TW98. The NLF benefit for this sized aircraft was assumed to be $30 \%$ chord laminar flow on the upper wing surface, $35 \%$ on both sides of the horizontal tail, and $23 \%$ for the vertical tail. All concepts were optimized for wing loading and thrust-to-weight (T/W) ratio, so the propulsion system was sized with the HLFC power requirements included. Given these assumptions, the HLFC system yielded lower fuel burn than the NLF design. This fuel burn advantage increased with increasing aircraft size. A more detailed trade study in this area is recommended to further explore this result; however, for the purposes of this study, HLFC was applied to all vehicle classes.

Based on flight test data as reported by Walsh, et. al. ${ }^{7}$, riblet technology was assumed to reduce the skin friction drag on the fuselage by $6 \%$ for the TW concepts, and by $6 \%$ on the HWB centerbody. In addition, a $1 \%$ drag reduction was assumed by utilizing variable trailing edge camber, a conservative assumption based on work done by Siclari, et. $\mathrm{al}^{8}$.

Weight reduction through advanced materials and structures technologies is another key area that can result in significant performance benefits. Carbon composite sandwich construction has been utilized extensively to improve stiffness, reduce weight, and reduce maintenance costs compared to traditional metallic construction. More recently, a new class of damage arresting stitched composites have been developed that have the potential to provide additional weight savings. One implementation of stitched composites that has shown promise not only to reduce weight, but manufacturing costs as well, is called PRSEUS (Pultruded Rod Stitched Efficient Unitized Structure) ${ }^{9}$. For the TW concepts, overall weight savings compared to metallic construction were assumed to be $23.5 \%$ for the wing and tail, and $14.5 \%$ for the fuselage. These assumptions were based on a $15 \%$ savings for the wing and tail and $5 \%$ for the fuselage for sandwich composites, and an additional 10\% weight savings for the stitched composites. In addition, based on a proprietary study by Boeing performed for NASA and the Air Force Research Lab in 2009, an active gust load alleviation system was assumed to reduce the weight of the bending material in the main wing by $1.7 \%$. Similar wing weight savings were assumed for the outer wing sections of the HWB concepts.

Several advanced subsystems were utilized in both the TW and HWB concepts. Electromechanical actuators (EMA) utilize electric motors that are mechanically coupled to the $\operatorname{load}^{10}$, eliminating the use of hydraulics. For the purposes of this study, a weight reduction was assumed equal to $10 \%$ of the traditional hydraulic system weight to account for the utilization of EMA. A hybrid solid oxide fuel cell/gas turbine (SOFC/GT) auxiliary power unit (APU) promises significantly greater fuel efficiency than the traditional APU and main engine generators, in addition to reducing emissions. ${ }^{11}$ A $1 \%$ fuel flow benefit was assumed through the use of this hybrid SOFC/GT APU during the cruise portion of the flight. The weight of the SOFC/GT APU was assumed to be equal to that of a traditional APU.

Finally, an advanced propulsion system was assumed that would utilize a large number of advanced engine component technologies that fit within a TRL $=6$ in 2020 timeframe. McKay ${ }^{12}$ presents projections of significant TSFC reductions for very high bypass ratio engine architectures in the 2020 timeframe based on these advanced component technologies. In addition, as part of a proprietary 2009 Boeing study performed for NASA and the AFRL, several advanced engine systems were modeled in detail that supported the TRL $=6$ in 2020 timeframe constraint. Based on these sources, a TSFC of 0.49 was assumed for the regional jet and large single aisle, and 0.46 was assumed for the three larger aircraft sizes. An uninstalled engine (including an integrated power system) T/W ratio of 4.0 was also assumed across the vehicle classes. Existing engine models were then scaled to match these parameters resulting in representative fuel flow and T/W performance for an advanced propulsion system. A more detailed engine design study in which each engine cycle is optimized for each air vehicle concept is possible, but was outside the scope of this effort. Since this study is focused on obtaining a relative comparison between the 
different vehicles, the result will be valid as long as consistent technology assumptions are applied across the vehicle concepts.

\section{Analysis Process}

The following sections describe the analysis process utilized to develop the advanced TW concepts, and the HWB concepts.

\section{A. Advanced TW Concept Design and Analysis}

Five baseline aircraft, currently in service, were selected to represent typical design missions across the range of vehicle classes including regional jets (RJ), large single aisle (LSA), small twin aisle (STA), large twin aisle (LTA), and very large (VL) . Table 2 shows the five aircraft and their relevant design parameters.

Table 2. Five Baseline Vehicles and their Relevant Design Parameters

\begin{tabular}{|c|c|c|c|c|c|c|c|}
\hline $\begin{array}{c}\text { Vehicle } \\
\text { Size } \\
\text { Class }\end{array}$ & $\begin{array}{c}\text { Baseline } \\
\text { Vehicle }\end{array}$ & Payload (lb) & $\begin{array}{c}\text { Design } \\
\text { Range } \\
(\mathrm{nm})\end{array}$ & TOGW (lb) & OEW (lb) & Cruise Mach & $\begin{array}{c}\text { Block } \\
\text { Fuel Burn } \\
(\mathrm{lb})\end{array}$ \\
\hline RJ & ERJ190 & 21,605 & 2400 & 114,552 & 64,300 & 0.78 & 23,800 \\
\hline LSA & $737-800$ & 37,760 & 2875 & 174,700 & 91,300 & 0.78 & 39,100 \\
\hline STA & $767-200$ ER & 44,500 & 6600 & 388,000 & 182,900 & 0.80 & 146,800 \\
\hline LTA & $777-200$ LR & 118,100 & 7500 & 768,000 & 342,900 & 0.84 & 279,800 \\
\hline VL & $747-400$ & 147,840 & 5800 & 877,000 & 394,700 & 0.85 & 298,600 \\
\hline
\end{tabular}

The baseline vehicles were modeled using NASA's Flight Optimization System (FLOPS) code. Three different sizing exercises were performed to develop the advanced TW concepts utilized for this study. First, FLOPS was calibrated to match performance for each of these five aircraft using a mixture of public and proprietary data by adjusting one or more parameters that affect empty weight, drag and fuel flow. Ideally, no calibration factors would be required; however, small adjustments are usually required to match the available data. Next, the technology assumptions described above were applied to size advanced TW concepts with the same mission assumptions and calibration factors as the baselines. The objective function for the optimizer was minimum takeoff gross weight, which provides a balanced design with low fuel burn and low weight/cost. Optimizing on fuel burn alone can result in heavier (and more expensive) concepts. The constraints were range, approach speed, takeoff and landing field length, missed approach thrust, second segment climb thrust, excess fuel capacity, and rate-of-climb (ROC) at cruise altitude. The design variables were wing loading and T/W ratio. Wing aspect ratio for all cases was 11.0, which was set as the upper limit. Table 3 shows the values set for each of these constraints for the five concepts. The parenthetical data are the results and the highlighted cells show the active constraint for each case.

Table 3. Constraint Summary for Advanced TW Concepts

\begin{tabular}{|r|r|c|c|c|c|c|}
\hline & & \multicolumn{5}{|c|}{ Constraint Values } \\
\hline Constraint & Units & TW98 & TW160 & TW216 & TW301 & TW400 \\
\hline Range & $\mathrm{nm}$ & $=2400(2400)$ & $=2875(2875)$ & $=6600(6600)$ & $=7500(7500)$ & $=5800(5800)$ \\
\hline Approach Speed & knots & $<135(127)$ & $<150(141)$ & $<140(121)$ & $<150(136)$ & $<145(145)$ \\
\hline Takeoff Field Length & feet & $<6745(6660)$ & $<9000(8830)$ & $<9000(6930)$ & $<10100(8970)$ & $<10500(9110)$ \\
\hline Landing Field Length & feet & $<4341(4290)$ & $<6200(5490)$ & $<5250(4680)$ & $<5600(5500)$ & $<6900(5920)$ \\
\hline Missed Approach Thrust & $\mathrm{lb}$ & $>0(3)$ & $>0(3070)$ & $>0(11,150)$ & $>0(15,650)$ & $>0(32,500)$ \\
\hline 2nd Segment Climb Thrust & $\mathrm{lb}$ & $>0(250)$ & $>0(4)$ & $>0(4300)$ & $>0(100)$ & $>0(15,900)$ \\
\hline Excess Fuel Capacity & $\mathrm{lb}$ & $>0(4030)$ & $>0(6760)$ & $>0(19)$ & $>0(4850)$ & $>0(78,250)$ \\
\hline ROC at Altitude & $\mathrm{ft} / \mathrm{min}$ & $>300(1930)$ & $>300(490)$ & $>300(303)$ & $>300(550)$ & $>300(430)$ \\
\hline
\end{tabular}

As expected, the application of the advanced technology assumptions resulted in significantly reduced weights and thrust requirements. Engine scale factors ranged from 0.5 to 0.7. Alternative engine models were then selected to better match the advanced concepts' thrust requirements, and the concepts were re-optimized, resulting in more reasonable engine scale factors. Finally, all calibration factors were removed to determine the magnitude of their impact on the optimized concepts. In all cases, the block fuel burn estimates were within $+/-2 \%$ of their previous 
values, indicating that FLOPS is relatively robust when applied to sizing TW concepts. Therefore, the advanced TW concepts developed for this study are FLOPS-optimized designs with no calibration factors, and should be considered all-new concepts rather than baseline vehicles with advanced technologies (i.e., an all new single aisle rather than a 737-800 with advanced technology applied). Table 4 presents a summary of the five advanced TW concepts.

Table 4. Summary of Key Parameters for the Advanced TW Concepts

\begin{tabular}{|c|c|c|c|c|c|c|c|}
\hline $\begin{array}{c}\text { Advanced } \\
\text { Tube+Wing }\end{array}$ & $\begin{array}{c}\text { Payload/Range } \\
(\mathrm{lb} / \mathrm{nm})\end{array}$ & TOGW (lb) & OEW (lb) & $\begin{array}{c}\text { Cruise } \\
\text { Mach }\end{array}$ & $\begin{array}{c}\text { Start of } \\
\text { Cruise } \\
\text { L/D }\end{array}$ & $\begin{array}{c}\text { Installed } \\
\text { Thrust per } \\
\text { Engine (lb) }\end{array}$ & $\begin{array}{c}\text { Block Fuel } \\
\text { Burn (lb) }\end{array}$ \\
\hline TW98 & $21,605 / 2400$ & 91,700 & 55,000 & 0.78 & 19.8 & 16,100 & 12,520 \\
\hline TW160 & $37,760 / 2875$ & 140,700 & 76,400 & 0.78 & 19.8 & 20,100 & 21,980 \\
\hline TW216 & $44,500 / 6600$ & 271,000 & 137,400 & 0.80 & 19.9 & 33,600 & 79,770 \\
\hline TW301 & $118,100 / 7500$ & 539,900 & 248,900 & 0.84 & 21.5 & 68,600 & 155,920 \\
\hline TW400 & $147,840 / 5800$ & 637,900 & 315,700 & 0.85 & 20.4 & 31,400 & 155,040 \\
\hline
\end{tabular}

\section{B. HWB Concept Design and Analysis}

A previous study presented the development of an HWB analysis capability in FLOPS, and noted that the largest areas of uncertainty were associated with the compressibility drag and centerbody weight estimates. ${ }^{13}$ Subsequent to that study, NASA has continued to improve and sponsor the development of a set of conceptual design tools for HWB concepts, with a focus on aerodynamics and weight estimation.

In a companion study by Gern ${ }^{14}$, a range of aerodynamic analysis tools were evaluated for application to HWB concepts. A set of wind tunnel test data for the Boeing BWB-450 configuration was utilized as the baseline case, and the BWB-450 tunnel model geometry was analyzed by a series of codes, starting with FLOPS and working up to a Navier-Stokes CFD code (FUN3D). Corrections were then made to the FLOPS-generated drag polar based on the test data and higher order analyses. Results from the corrected FLOPS aerodynamics analysis were then checked by two methods. The first utilized a Boeing trend line analysis relating maximum cruise L/D to the square root of wetted aspect ratio, as presented by Pitera ${ }^{15}$, et. al. This trend line analysis provides an upper practical limit on cruise L/D. The second utilized a vortex lattice analysis with a theoretical viscous correction, as described by Gern.

A higher order centerbody weight estimation methodology was also developed to support the design of the HWB concepts by Gern ${ }^{16}$. A finite element model of the HWB centerbody and outer wing sections was created from Vehicle Sketch Pad (VSP) geometry input and analyzed in NASTRAN for each of the five HWB concepts. Figure 1 illustrates the VSP to NASTRAN geometry translation.

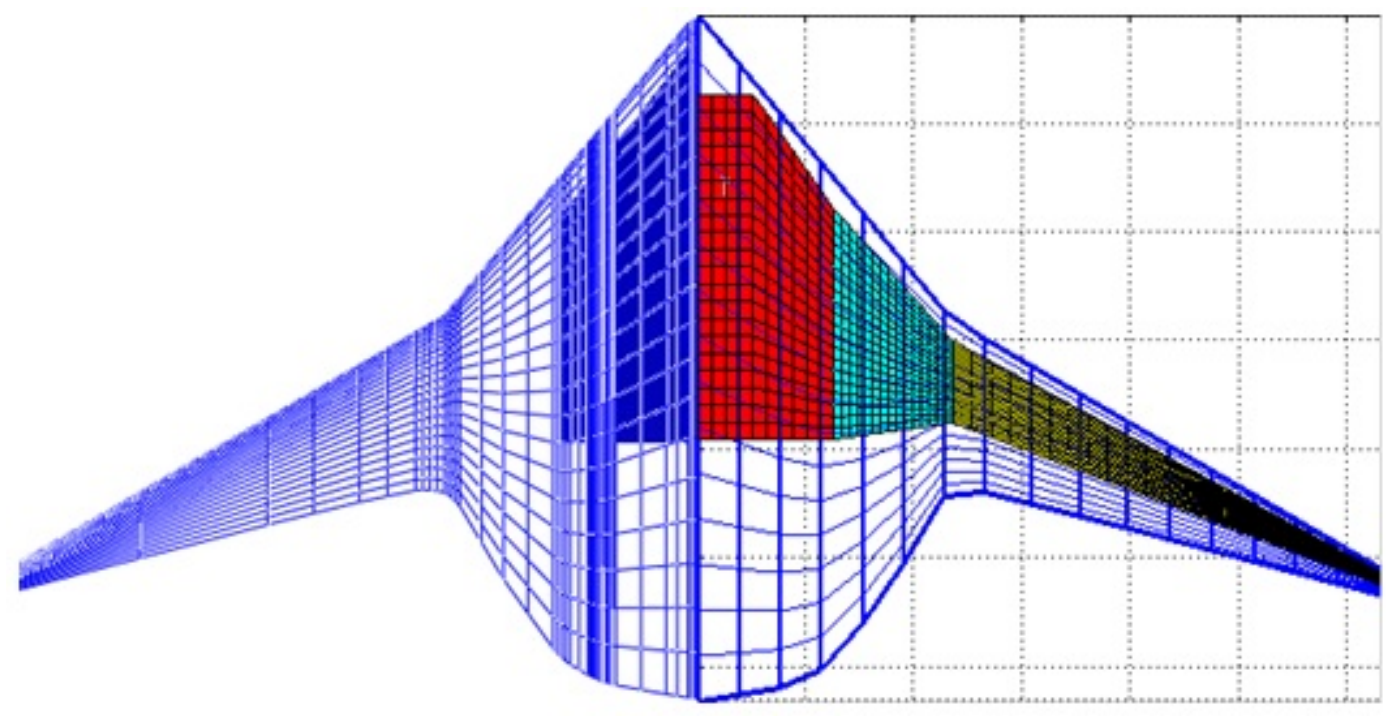

Figure 1. VSP to NASTRAN geometry translation for the HWB216. 
The left side of Figure 1 is the VSP model for the wing and pressurized cabin (solid blue). The right side is the FEM layout, showing the pressurized cabin, wing transition, and outboard wing box. The NASTRAN analysis included aerodynamic modeling to obtain the load conditions utilized for the structural optimization. Maximum stress, displacement, and minimum gauge constraints were applied and the primary centerbody structural weight was estimated, assuming the use of stitched composites. Weight allocations for the secondary structure, cockpit, and cutouts were then applied to produce an as-built centerbody weight estimate.

Given the development of improved aerodynamic and centerbody weight estimation capability, the design of the five HWB concepts proceeded as described below.

The first step was to create a 2D layout of the cabin, in order to begin sizing the centerbody. TW cabin layouts were utilized to identify the required seating, aisle, galley, lavatory, and other spaces in the passenger cabin. The HWB cabin layout was then created utilizing a home-plate shaped centerbody and matching the areas to the maximum extent possible that were identified from the equivalent TW baseline concept. Figure 2 shows the 767$200 \mathrm{ER}^{17}$, and Figure 3 the equivalent HWB concept, the HWB216, as an example (dimensions in inches).

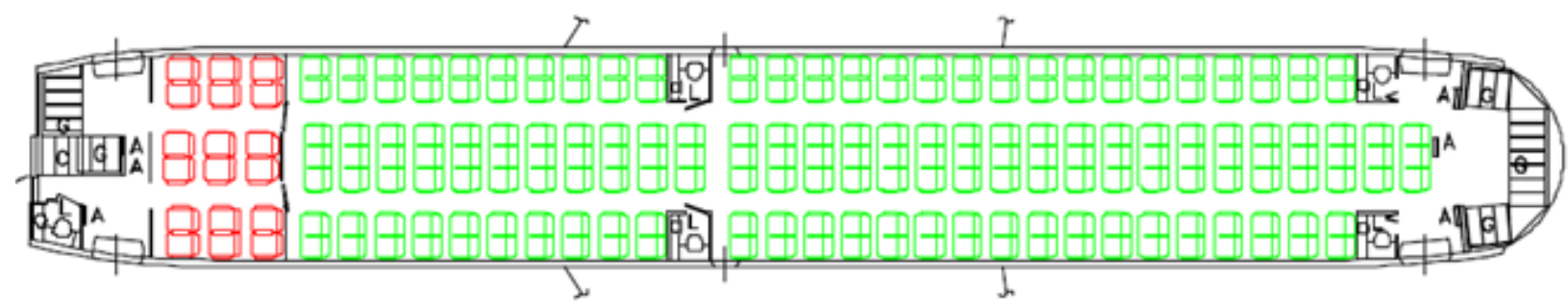

Figure 2. 767-200ER cabin layout.

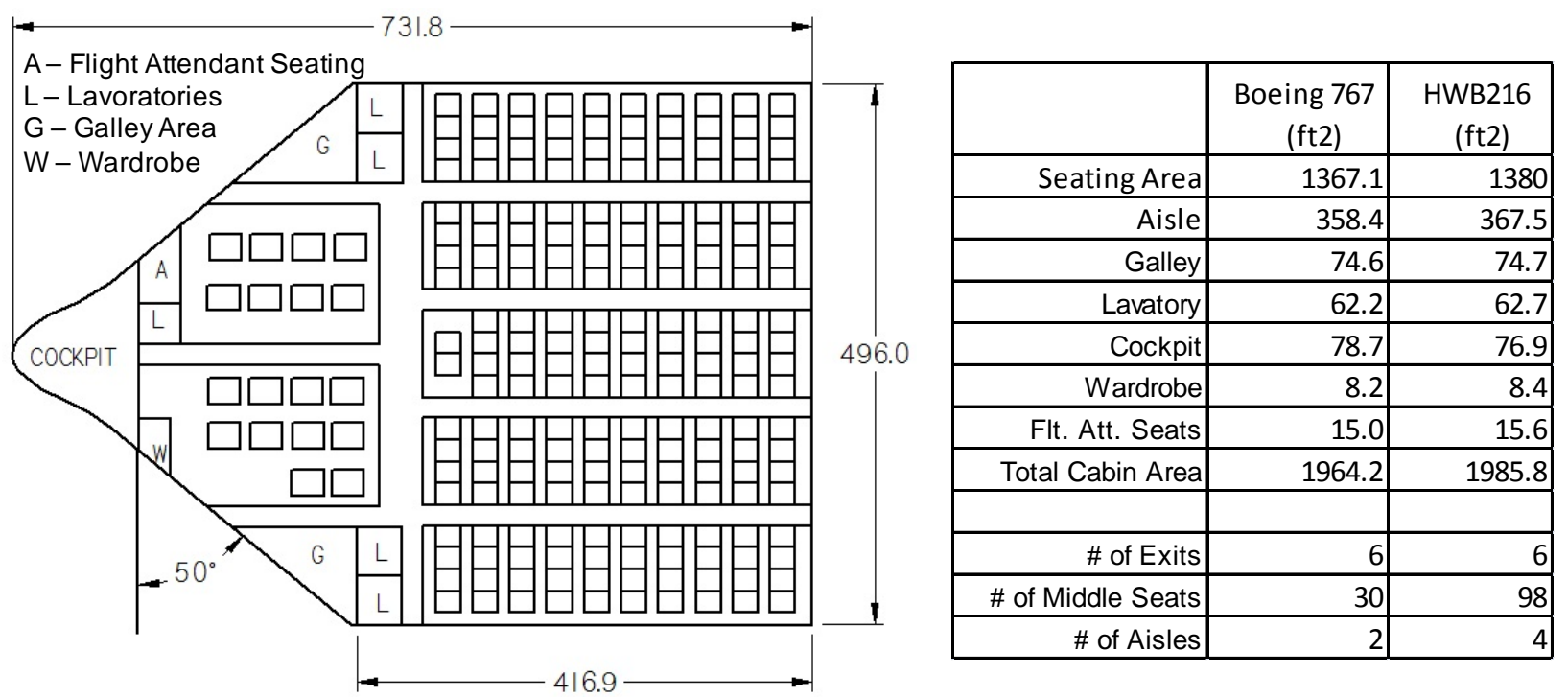

Figure 3. HWB216 cabin layout and associated area data.

Total cabin area of the HWB is within $1 \%$ of the 767 baseline/TW216 concept. The same number of exits was utilized; four through the rear bulkhead at the ends of the aisles and two through the leading edge of the centerbody. The HWB layout has four aisles compared to two for the TW216; however, there are an additional 68 middle seats in the HWB layout. Similar layouts were created for the other four HWB concepts, and total cabin areas were within $1 \%$ of their TW counterparts except in the case of the HWB98 concept. The ERJ190 cabin area is $~ 717 \mathrm{ft} 2$, and the HWB98 cabin area is $766 \mathrm{ft} 2$. The additional area in the HWB concept comes from additional aisle area that was required to fit the home-plate shape, provide the required number of emergency exits, and keep the seating a maximum of three abreast. There are 32 middle seats and three aisles in the HWB98 concept compared to zero middle seats and one aisle for the ERJ190. 
In addition to the cabin area, a pressurized cargo and baggage hold is required. 2D cross-sections were created, including a $4 \mathrm{ft}$ depth baggage compartment below the passenger cabin. Figure 4 illustrates several 2D crosssections for the HWB216, dimensions are in inches.
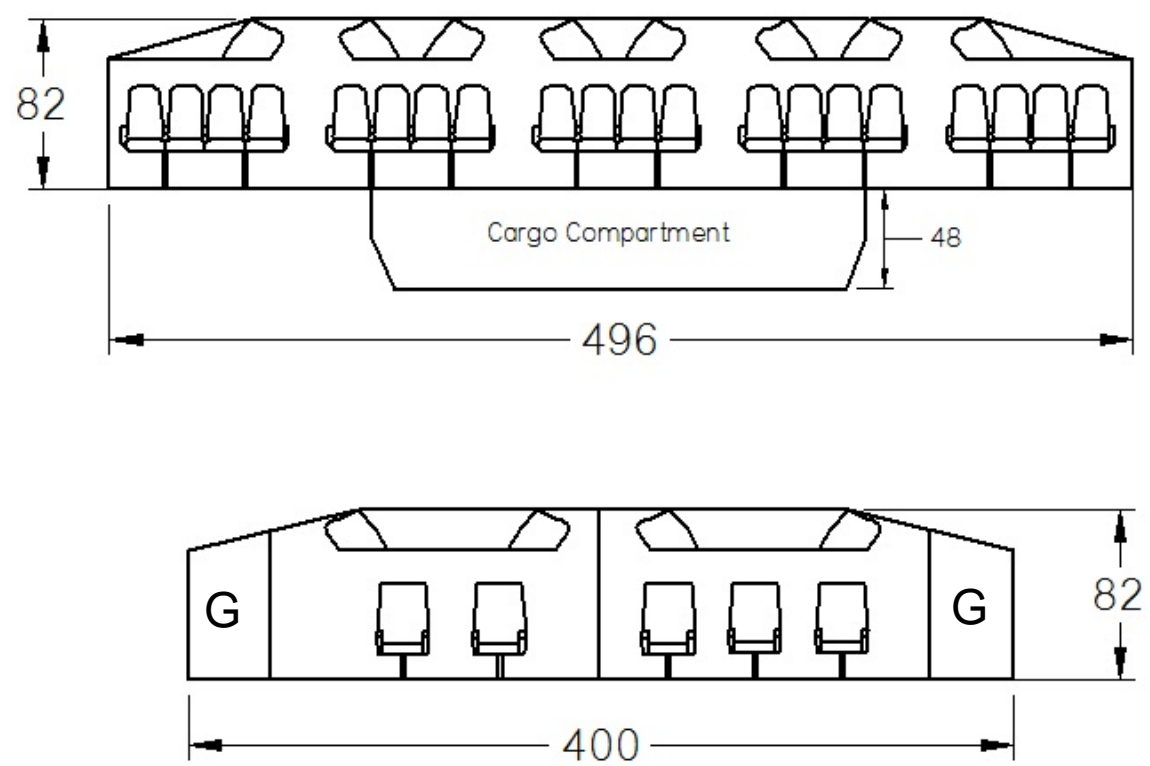

Figure 4. HWB216 cabin cross sections.

The cross section on the top shows the main cabin area, the one on the bottom shows the first class area in the forward section with galley space on either side. The cabin height is $\sim 7 \mathrm{ft}$, similar to the 767. Similar 2D crosssectional layouts for the other four HWB concepts were created.

The next step was to create a 3D model utilizing information from the 2D layouts. 3D components were quickly created utilizing VSP to represent the pressurized cabin and cargo volumes. Airfoils were then wrapped around these volumes, with the objective of finding a balance between airfoil thickness and chord length. Shorter chords reduce overall wetted area, but increase the airfoil thickness, which increases drag. Conversely, longer chords allow the use of thinner airfoil sections, however overall wetted area increases which also increases drag. To maximize cruise $\mathrm{L} / \mathrm{D}$, a minimum wetted area with maximum span is desired. HWB configurations tend to optimize at higher wingspans than their tube and wing counterparts, although the overall footprint of the HWB is competitive due to the significantly decreased length. The HWB216, 301 and 400 concepts achieved a reasonable airfoil thickness-tochord ratio as a function of semi-span; however, the HWB98 and HWB160 concepts presented a challenge. Since people don't scale down, the required cabin and baggage heights remain relatively constant, resulting in extremely thick airfoil sections without resorting to unreasonable chord lengths. To solve this challenge, the baggage compartment was relocated to the passenger cabin level by increasing the pressurized cabin width and including the required volume on both sides of the passenger cabin. This reduced the required centerbody depth and resulted in a reasonably balanced design. Figure 5 illustrates the tightly wrapped passenger and cargo volumes for the HWB301.

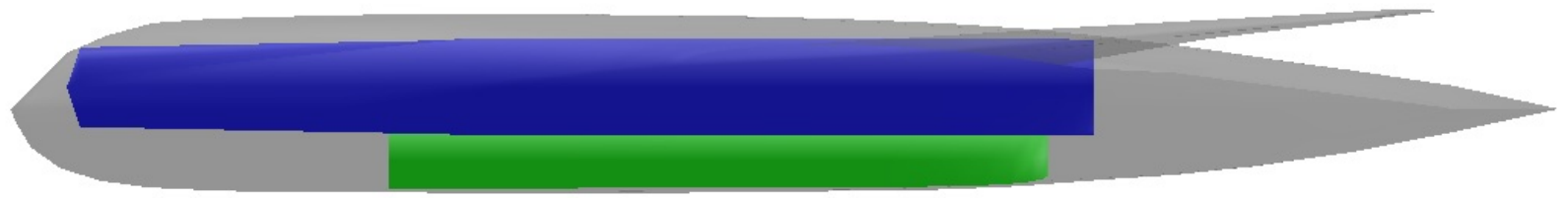

Figure 5. Side view of HWB301 with passenger cabin (blue) and cargo/baggage hold (green). 
Figure 6 illustrates the same view for the HWB98. Note that there is no under floor cargo/baggage area. Although this helped keep the thickness and wetted area reasonable as discussed above, a new challenge was created regarding the packaging of the nose landing gear. Figure 5 clearly shows there is adequate room forward of the cargo/baggage area under the main cabin for the nose gear, however this is not true for the HWB98. Assuming a 24inch tire diameter (similar to the ERJ190), the nose gear wheels would not fit within the available space. A bump out or blister on the underside of the HWB to accommodate the wheels would have a significant drag impact. The solution was to assume a pivoting nose gear wheel assembly, as shown in Figure 6 by the two black tires rotated 90 degrees and stowed within the outer mold line. This adds to the complexity and cost of the nose gear, however, no alternative was found that was preferable.

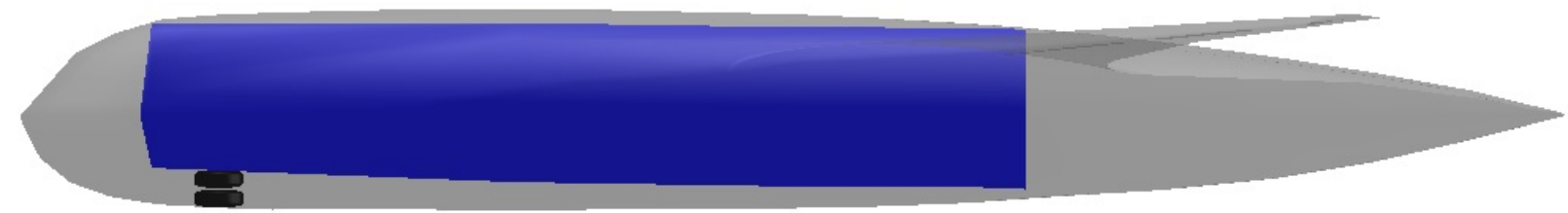

Figure 6. Side view of HWB98 (note: not shown to the same scale as Figure 5).

Next, engines were located on the aft section of the centerbody. One of the key features of the HWB is the potential for significant noise reduction due to the shielding of the top-mounted engines by the body. Thomas ${ }^{18}$, et. al., performed a HWB system noise assessment that demonstrated the potential for the HWB to meet the ERA noise goal of $42 \mathrm{db}$ cumulative below the Stage 4 certification level. Engines were located two fan nozzle diameters upstream of the trailing edge. Vertical surfaces were also investigated for their noise shielding potential, but the verticals resulted in a slight noise increase. Therefore, the HWB concepts in this study utilize winglets with rudders to aid in lateral control, and the engines are located two fan exit diameters upstream of the trailing edge. Propulsion airframe integration for this engine location is challenging due to the higher flow field velocities present in this region. For the purposes of this study, it is assumed an aerodynamically efficient integration can be achieved through simultaneous shape optimization of the engine nacelle/pylon and centerbody upper surface. Traditional, under-wing podded engine integration is much less challenging for the advanced TW concepts. For these concepts, an engine integration weight factor is applied equal to $5 \%$ of the uninstalled integrated power and propulsion system weight. For the HWB concepts, a 12\% weight factor was applied, to account for the pylon weight and additional support structure required for a top-mounted engine installation. The same advanced engine parameters and engine decks were utilized for both the advanced TW concepts and the HWB concepts, except for the case of the TW400/HWB400. The TW400 is a four-engine design, while the HWB400 is a three-engine design, requiring higher thrust engines.

Once the engine locations were selected, other major components were arranged to enable a longitudinal CG calculation. The fuel tanks, landing gear, auxiliary power unit, and avionics bays were arranged with the goal of locating the CG approximately coincident with the AC, or neutral point, and close to $40 \%$ of the MAC at cruise conditions. Previous Boeing studies have shown that keeping the CG and AC close to 40\% MAC results in a reasonably well balanced design. Figure 7 shows the internal arrangement of these major components for the HWB301 concept. 


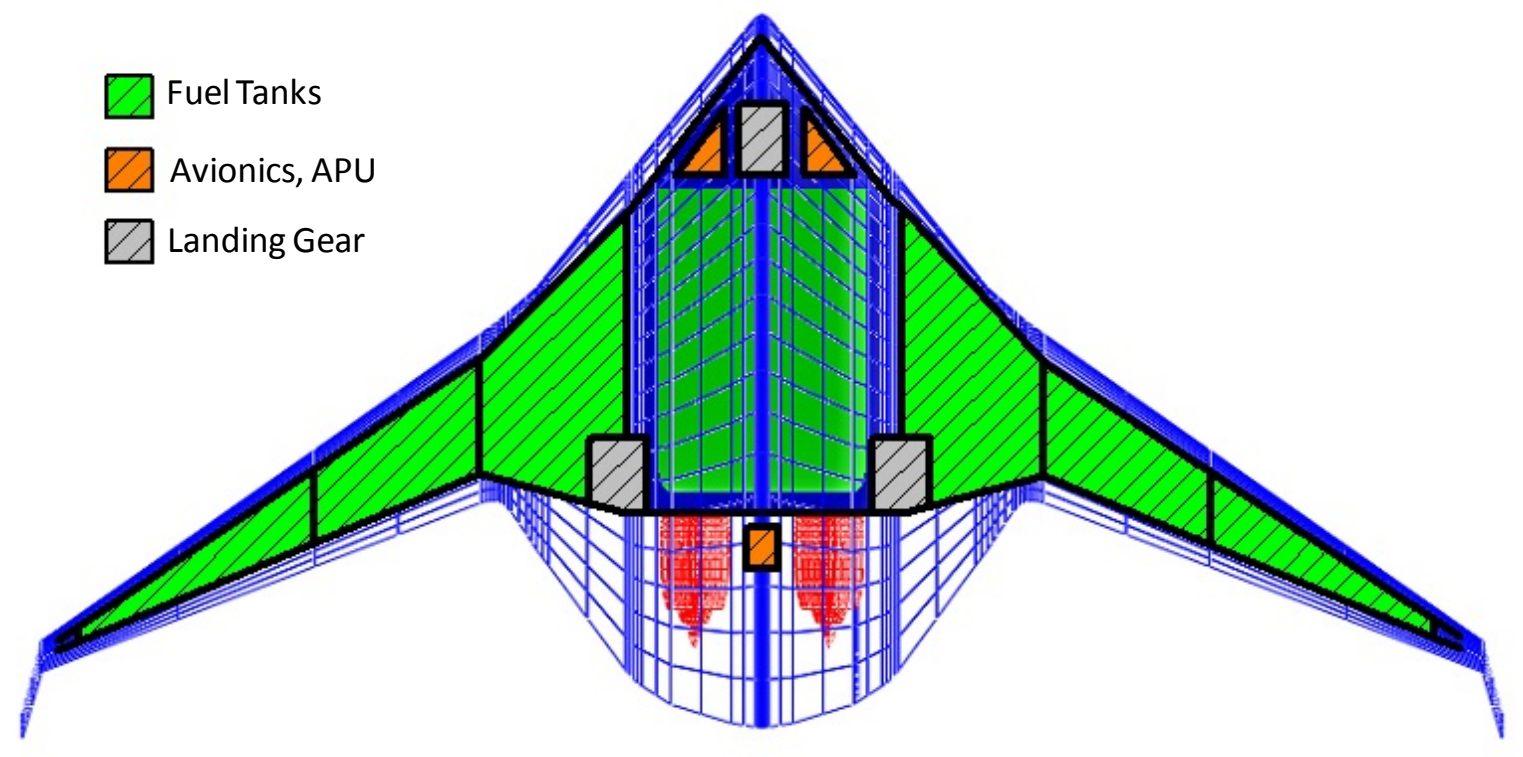

Figure 7. HWB301 internal arrangement of major components.

The avionics bays are placed on either side of the nose landing gear, and the APU is placed between the engines. Figure 7 is a bottom view of the aircraft, showing the green, rectangular cargo/baggage area in the center of the aircraft. The blue, "home-plate" shaped area behind the cargo/baggage area between the fuel tanks is the passenger cabin. In all cases there was more than adequate fuel tank volume available. Given this layout of the major internal components, FLOPS was utilized to calculate the longitudinal CG. The twist and camber of the outer wing sections was then adjusted to yield as close to an elliptical load distribution as possible, utilizing VSP and a generalized vortex lattice method called Vorlax ${ }^{19}$. Vorlax was then utilized to calculate the AC at the cruise condition. The MAC was determined using a simple area weighted average calculation. Results for these parameters for each of the five HWB concepts are shown in Table 5.

Table 5. Longitudinal Static Stability Parameters for the HWB Concepts

\begin{tabular}{|c|c|c|c|c|c|c|}
\hline & $\begin{array}{c}\text { Fuselage } \\
\text { Length (ft) }\end{array}$ & MAC (ft) & $\begin{array}{c}\text { Distance from } \\
\text { nose to CG (ft) }\end{array}$ & $\begin{array}{c}\text { Distance from } \\
\text { nose to AC (ft) }\end{array}$ & $\begin{array}{c}\text { CG location } \\
\text { as \% MAC }\end{array}$ & $\begin{array}{c}\text { Static } \\
\text { Margin }\end{array}$ \\
\hline HWB98 & 65.7 & 40.8 & 33.5 & 33.8 & 37 & 0.7 \\
\hline HWB160 & 80.7 & 48.6 & 41.0 & 41.4 & 40 & 0.8 \\
\hline HWB216 & 105.0 & 63.4 & 53.7 & 53.1 & 39 & -0.9 \\
\hline HWB301 & 118.0 & 68.6 & 62.0 & 61.7 & 41 & -0.4 \\
\hline HWB400 & 135.0 & 82.2 & 69.7 & 70.6 & 40 & 1.1 \\
\hline
\end{tabular}

The CG for the HWB98 is slightly forward of the desired location, and the HWB301's CG is slightly aft of the desired location, however, the excess fuel volume available should enable the CG positions to be adjusted as needed by placement and management of the reserve and mission fuel.

FLOPS was then utilized to size the engines and estimate the mission performance for each of the five HWB concepts. The HWB planform area was manually adjusted to maximize wetted aspect ratio with minimum weight. Wing spans were not constrained to be less than or equal to their TW counterparts, therefore airport compatibility issues may be more of a challenge for the HWB concepts. All mission profile and technology assumptions utilized for the advanced TW concepts were consistently applied to the HWB concepts with the only exceptions being obvious cases of configuration unique characteristics, such as the engine installation. Table 6 presents a summary of the key parameters for the five HWB concepts. 
Table 6. Summary of Key Performance Parameters for the HWB Concepts

\begin{tabular}{|c|c|c|c|c|c|c|c|}
\hline HWB & $\begin{array}{c}\text { Payload/Range } \\
(\mathrm{lb} / \mathrm{nm})\end{array}$ & TOGW (lb) & OEW (lb) & $\begin{array}{c}\text { Cruise } \\
\text { Mach }\end{array}$ & $\begin{array}{c}\text { Start of } \\
\text { Cruise } \\
\text { L/D }\end{array}$ & $\begin{array}{c}\text { Installed } \\
\text { Thrust per } \\
\text { Engine (lb) }\end{array}$ & $\begin{array}{c}\text { Block Fuel } \\
\text { Burn (lb) }\end{array}$ \\
\hline HWB98 & $21,605 / 2400$ & 101,000 & 63,300 & 0.78 & 20.7 & 14,300 & 13,020 \\
\hline HWB160 & $37,760 / 2875$ & 166,100 & 100,800 & 0.78 & 23.1 & 22,200 & 22,860 \\
\hline HWB216 & $44,500 / 6600$ & 286,900 & 155,000 & 0.80 & 22.3 & 35,500 & 77,930 \\
\hline HWB301 & $118,100 / 7500$ & 542,600 & 261,300 & 0.84 & 23.5 & 70,000 & 146,620 \\
\hline HWB400 & $147,840 / 5800$ & 693,600 & 372,200 & 0.85 & 23.7 & 59,900 & 147,850 \\
\hline
\end{tabular}

Comparing to the advanced TW results in Table 4, it is clear that the HWB concepts have greater operating empty weights, and gross weights. The HWB400 is a three-engine concept, whereas the TW400 is a four-engine design. All other HWB and TW concepts are twin-engine designs. The HWB concepts also have better cruise L/D performance, and more favorable block fuel burn in the case of the three larger designs. Figure 8 shows a scaled top view of the five HWB concepts with associated wing spans. For comparison purposes, the wing spans of the advanced TW concepts are 101,116, 167, 206, and, $233 \mathrm{ft}$, respectively.

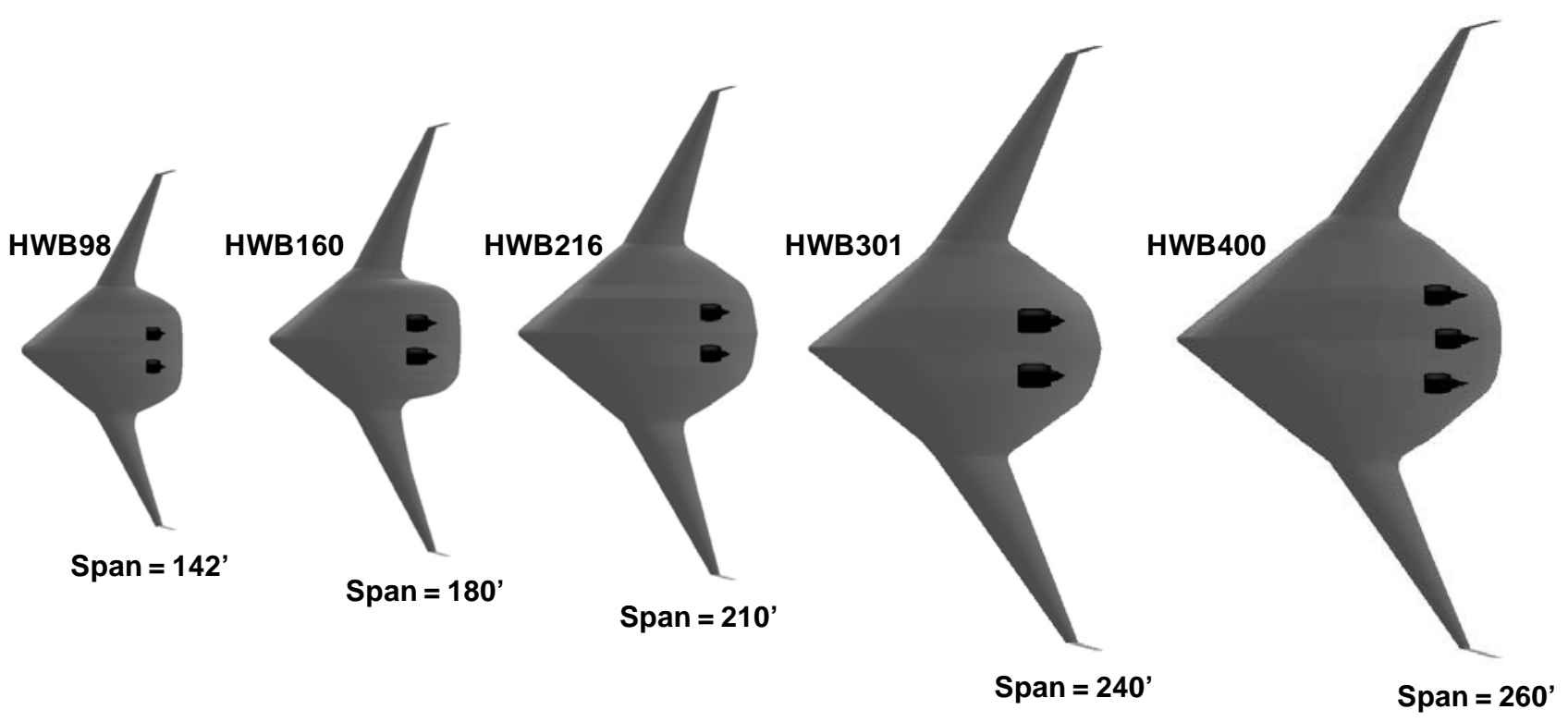

Figure 8. Scaled top-view of the five HWB concepts and associated wing spans.

\section{Results}

The block fuel burn estimates for the advanced TW and HWB concepts are shown in Table 7, as well as the \% fuel burn benefit. A negative \% fuel burn benefit indicates that the advanced TW concept has less block fuel burn than its HWB counterpart. 
Table 7. Advanced TW to HWB Block Fuel Burn Comparison

\begin{tabular}{|c|c|c|r|l|}
\hline $\begin{array}{c}\text { Passenger } \\
\text { Count }\end{array}$ & $\begin{array}{l}\text { TW Block } \\
\text { Fuel Burn (lb) }\end{array}$ & $\begin{array}{l}\text { HWB Block } \\
\text { Fuel Burn (lb) }\end{array}$ & Delta (lb) & $\begin{array}{l}\text { \% Fuel } \\
\text { Burn Benefit } \\
\text { of HWB }\end{array}$ \\
\hline 98 & 12,520 & 13,020 & -500 & -4.0 \\
\hline 160 & 21,980 & 22,860 & -880 & -4.0 \\
\hline 216 & 79,770 & 77,930 & 1,840 & 2.3 \\
\hline 301 & 155,920 & 146,620 & 9,300 & 6.0 \\
\hline 400 & 155,040 & 147,850 & 7,190 & 4.6 \\
\hline
\end{tabular}

Both the HWB98 and HWB160 burn 4\% more fuel than their advanced TW counterparts. However, once the payload/range increases to the small twin aisle size class, the HWB shows a fuel burn benefit, which increases to $6 \%$ with the large twin aisle size. The very large size class shows a $4.6 \%$ benefit, indicating that larger passenger count (i.e., payload) does not necessarily lead to a larger fuel burn benefit. A combination of payload and range should be considered. Figure 9 plots the \% fuel burn benefit of the HWB vs. the product of payload (tons) and range (nm K).

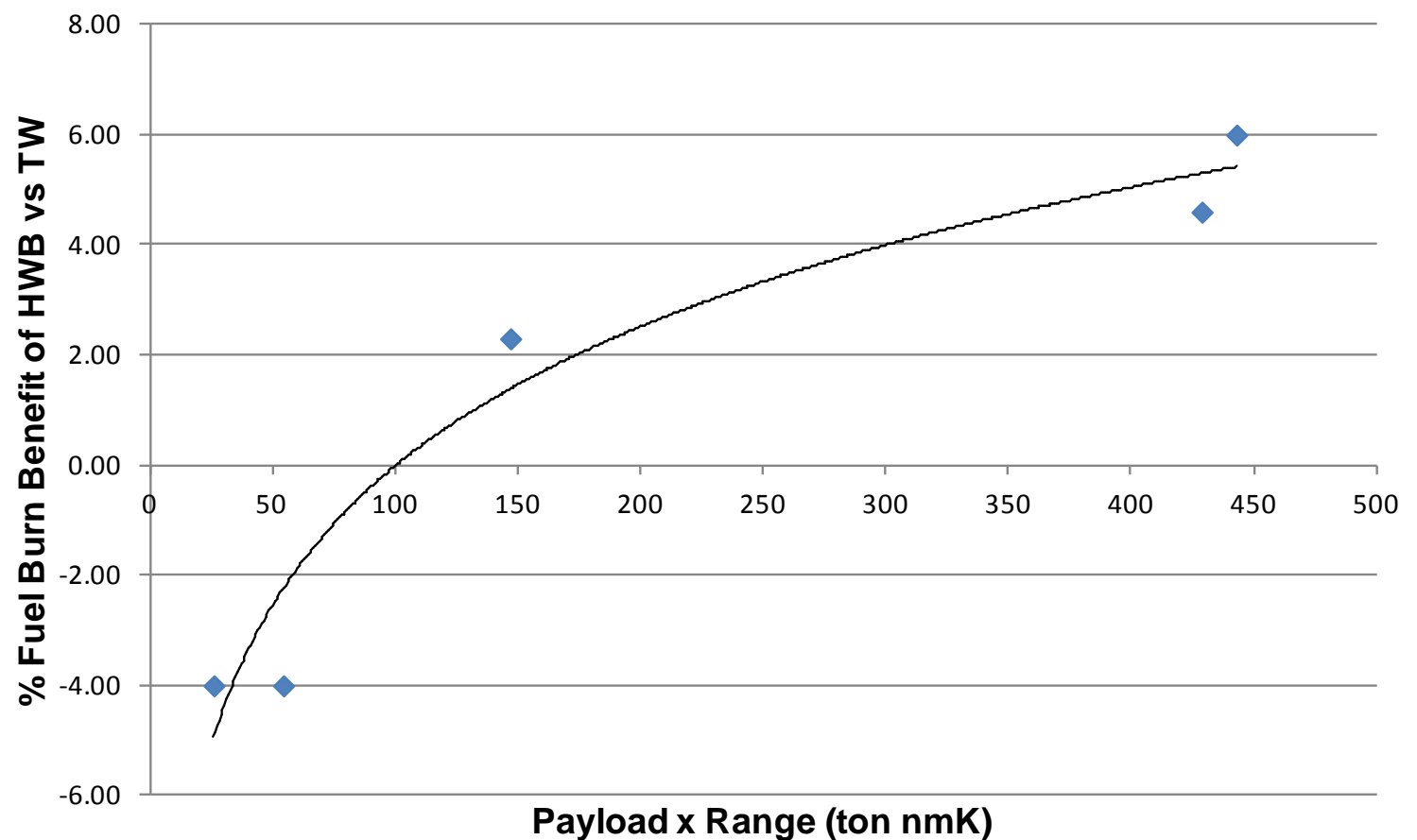

Figure 9. \% Fuel Burn Benefit of HWB vs. Payload x Range.

A logarithmic curve fit was utilized to plot the trend line in Figure 9, which shows the fuel burn benefit rapidly increasing non-linearly when moving from the HWB160 to the HWB216, before leveling off to a more linear trend approaching the HWB301 and HWB400 sizes. Note that the payload x range (PR) parameter for the HWB400 is slightly less than the HWB301, due to the smaller design range of the 400 passenger class aircraft. In addition, the HWB98 and HWB160 have payload x range parameters very close together, as do the HWB301 and HWB400. Additional data points falling between these two end points would be helpful to provide confidence in the trend line result. Therefore, two additional design cases were developed; an extended range TW160ER/HWB160ER, and a shorter range TW301SR/HWB301SR. The TW160 was re-sized for a design range of 5000 nm (originally 2875 $\mathrm{nm}$ ), and the TW301 was re-sized to a design range of $4200 \mathrm{~nm}$ (originally $7500 \mathrm{~nm}$ ). This yielded a payload x range parameter value of 94 for the new 160 passenger class vehicles, and 248 for the new 301 passenger class vehicles. Since the payload was held constant, the new HWB planform areas were not altered, however the fuel load and engine thrust was sized for the new design ranges. In the case of the HWB160, there was enough excess fuel volume to accommodate the required amount of fuel to increase the design range to $5000 \mathrm{~nm}$. The increased fuel

American Institute of Aeronautics and Astronautics 
weight caused increases in sub-system weights, thrust required and therefore propulsion system weight, and structural weight. The OEW for the HWB160 increased from 100,800 lb to 104,100 lb, and the gross weight increased from 166,100 lb to 187,350 lb. The reverse was true in the case of the HWB301 reduced range design. Gross weight decreased by $81,760 \mathrm{lb}$, and OEW decreased by 8,500 lb. Figure 10 is the same plot shown in Figure 9 , with the two additional design points included, and the trend line updated.

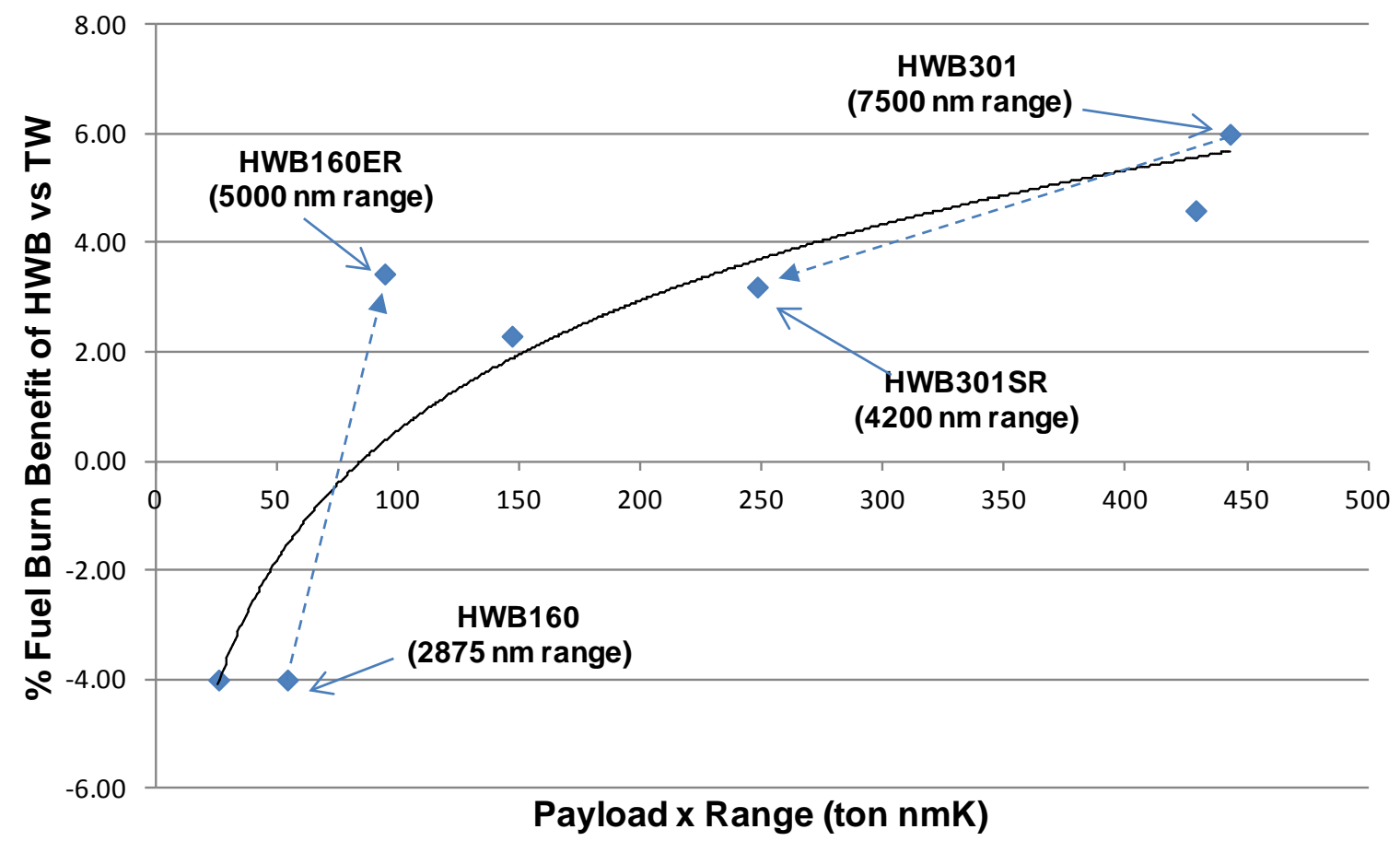

Figure 10. \% Fuel Burn Benefit of HWB vs. Payload $x$ Range including two additional design cases.

These two additional points confirm the original trend line by showing an initial steep increase in fuel burn benefit that levels off into a linear trend at the larger payload $\mathrm{x}$ range values. The new trend line shows a break-even point of 86, i.e., for designs with payload (tons) x range (nm K) values greater than 86, an HWB configuration will have a block fuel burn benefit over an equivalent technology TW configuration. In addition, it is clear from this data that the HWB configuration is ideally suited for moderate payload, long range design missions, since adding additional fuel has minimal impact to the configuration relative to a TW design. Conversely, the benefits of the HWB are less for higher payload, shorter range missions. An HWB configuration designed for a high payload, long range mission would optimize at a high wing span, and could present airport compatibility challenges.

Although the uncertainty in the areas of aerodynamics and centerbody weight estimation has been reduced relative to earlier studies, until a large scale HWB aircraft is built and tested, uncertainty will remain. For this reason, a sensitivity study was performed. For all seven HWB concepts, the empty weight was varied by $+/-10 \%$. Figure 11 shows the results, with the blue diamonds representing the baseline curve shown in Figure 10. 


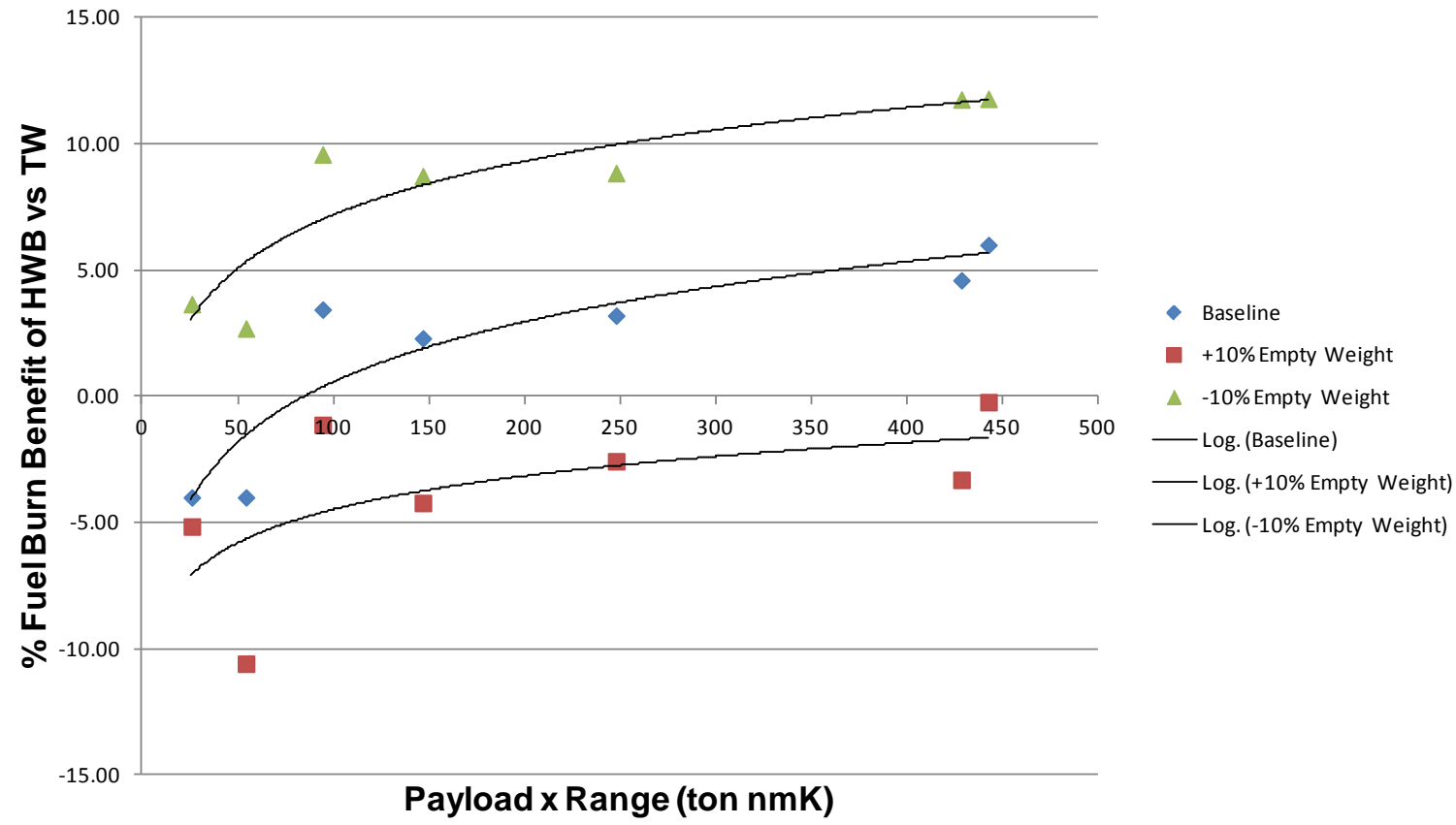

Figure 11. Empty weight sensitivity study results.

The red squares represent HWB data points with a 10\% empty weight increase, and the green triangles represent a $10 \%$ empty weight decrease. It is clear that the block fuel burn is sensitive to the empty weight estimate. If the HWB empty weight is $10 \%$ higher than estimated (and the advanced TW concepts have no weight increase), the HWB fuel burn benefit is negated. Conversely, if the HWB empty weight is $10 \%$ less than predicted in this study (everything else remaining equal), the HWB concepts maintain a fuel burn benefit across the entire range of vehicle size classes.

Next, a drag sensitivity study was performed. The overall drag of the HWB concepts was varied by $+/-10 \%$, and the results are plotted in Figure 12. The red squares represent a 10\% overall drag increase, and the green triangles a $10 \%$ drag decrease.

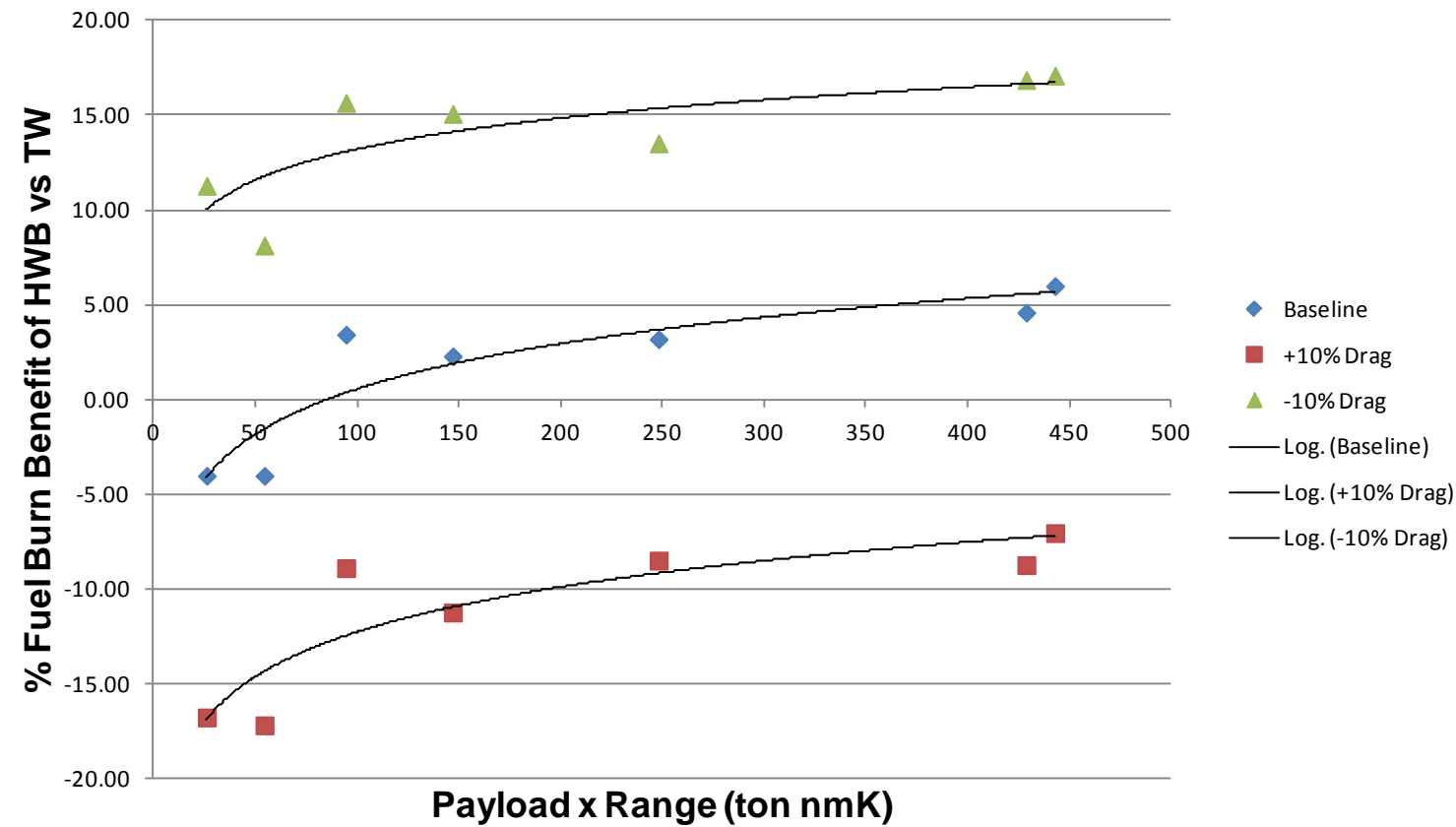

Figure 12. Drag sensitivity study results. 
The HWB fuel burn benefit estimate is also sensitive to the overall drag estimate, and, comparing Figures 11 and 12, it is clear that the HWB concepts are more sensitive to drag changes than to weight. Similar to the weight sensitivity, if the drag is $10 \%$ greater than estimated, none of the HWB concepts show a fuel burn benefit, however, if the drag is reduced by $10 \%$ (everything else remaining equal), the HWB concept becomes favorable across all of the vehicle size classes in terms of fuel burn benefit compared to the advanced TW concepts.

\section{Conclusion}

The results presented in the previous section show that the HWB configuration has the potential to deliver a fuel burn benefit compared to an equivalent technology TW configuration. However, the magnitude of this potential fuel burn benefit is a function of the payload and range of the design. The HWB configuration is best suited for long range design missions with medium to large payloads. The product of payload (tons) and range (nm K) was utilized as a metric to quantify the relative HWB fuel burn benefit. The results show that a PR value of 86 or greater yields an HWB with a fuel burn benefit compared to a TW. This PR value translates to an aircraft sized to a payload and range between that of a 737 and a 767. The HWB configurations developed for this study had higher wingspans than their TW counterparts in order to maximize their aerodynamic efficiency. As payload requirements increase, the HWB configuration, while continuing to show improved fuel burn benefits over a TW configuration, will encounter airport compatibility challenges due to the large spans required. Therefore, a long range, moderate payload design mission appears to be the best fit for an HWB configuration when considering factors other than purely relative fuel burn benefits.

The sensitivity studies presented in the previous section illustrate the importance of reducing the uncertainties in drag and weight estimation. A $10 \%$ increase in HWB empty weight would erase all fuel burn benefits relative to a TW concept. Conversely, a 10\% decrease in HWB empty weight would result in a fuel burn benefit across all PR values for the HWB. The drag sensitivity study showed similar, but more pronounced, results. An important consideration, however, is that these sensitivity studies were performed by perturbing only one parameter and holding all others constant. Changes to the assumed technology benefits would most likely apply to both the TW and HWB concepts equally, therefore not significantly impacting the relative fuel burn values. Changes that are unique to the HWB configuration, such as the centerbody weight, would have an impact on the relative fuel burn

performance. In the case of the HWB301, the centerbody weight is $20 \%$ of the total OEW, so a $10 \%$ increase in centerbody weight would increase the OEW by only 2\%.

Given a well-suited set of requirements, the HWB configuration has the potential to simultaneously reduce fuel burn and noise compared to an equivalent technology TW configuration. Uncertainties will remain, however, in the estimated performance of the HWB until large scale testing is performed.

\section{Acknowledgments}

The author is grateful for the contributions of Dr. Frank Gern (NASA Langley Research Center), Doug Wells (NASA Langley Research Center), Andy Hahn (NASA Langley Research Center), Luke Murchison (Co-op student, NASA Langley Research Center), and Lara Janse Van Vuuren (Mentorship Student, NASA Langley Research Center). This study was supported by Dr. Fay Collier under NASA’s Environmentally Responsible Aviation project. 


\section{References}

${ }^{1}$ Liebeck, R.H., Page, M.A., Rawdon, B.K., Scott, P.W., and Wright, P.A., “Concepts for Advanced Subsonic Transports”, NASA CR-4624, September, 1994.

${ }^{2}$ Liebeck, R.H., Page, M.A., Rawdon, B.K., "Blended-Wing-Body Subsonic Commercial Transport”, AIAA 980438, January, 1998.

${ }^{3}$ Roman, D., Allen, J.B., Liebeck, R.H., "Aerodynamic Design Challenges of the Blended-Wing-Body Subsonic Transport”, AIAA-2000-4335.

${ }^{4}$ Liebeck, R.H., "Design of the BWB Subsonic Transport”, AIAA-2002-0002, January, 2002.

${ }^{5}$ Liebeck, R.H., "Blended Wing Body Design Challenges”, AIAA-2003-2659, July, 2003.

${ }^{6}$ Collier, F., Thomas, R., Nickol, C., Lee, C., Tong, M., "Environmentally Responsible Aviation - Real Solutions for Environmental Challenges Facing Aviation”, $27^{\text {th }}$ International Congress of the Aeronautical Sciences (ICAS), September, 2010.

${ }^{7}$ Walsh, M.J., Sellers, W.L., McGinley, C.B., "Riblet Drag Reduction at Flight Conditions", AIAA-1988-2554, June, 1988.

${ }^{8}$ Siclari, M.J., Austin, F., Van Nostrand, W., and Volpe, G., “Optimization of segmented flaps for in-flight transonic performance enhancement”, AIAA 97-0516, January, 1997.

${ }^{9}$ Velicki, A., and Jegley, D., "PRSEUS Development for the Hybrid Wing Body Aircraft", AIAA 2011-7025, September, 2011.

${ }^{10}$ Blanding, D., "Subsystem Design and Integration for the More Electric Aircraft", AIAA 2007-4828, June, 2007.

${ }^{11}$ Daggett, D., Rajashekara, K., and Grieve, J., "Solid Oxide Fuel Cell/Gas Turbine Hybrid APU System for Aerospace Applications”, IEEE-4244-0365-0 (2006).

${ }^{12}$ McKay, B. G., "Next Generation Propulsion \& Air Vehicle Considerations”, AIAA-2009-4803, August, 2009.

${ }^{13}$ Nickol, C.L., McCullers, L.A., "Hybrid Wing Body Configuration System Studies", 47 ${ }^{\text {th }}$ AIAA-2009-931, AIAA Aerospace Sciences Meeting, 5-8 January 2009.

${ }^{14}$ Gern, F.H., "Improved Aerodynamic Analysis for Hybrid Wing Body Conceptual Design Optimization,” accepted for 50th AIAA Aerospace Sciences Meeting, Nashville, Tennessee, January, 2012.

${ }^{15}$ Pitera, D.M., DeHaan, M., Brown, D., Kawai, R.T., Hollowell, S., Camacho, P., Bruns, D., and Rawdon, B.K., "Blended Wing Body Concept Development with Open Rotor Engine Integration”, NASA CR-2011-217303, November, 2011.

${ }^{16}$ Gern, F.H., "Improved Structural Analysis for Hybrid Wing Body Conceptual Design Optimization,” accepted for 53rd AIAA/ASME/ASCE/AHS/ASC Structures, Structural Dynamics and Materials Conference, Honolulu, Hawaii, April, 2012.

${ }^{17}$ Boeing Airport Compatibility Documentation, http://www.boeing.com/commercial/airports/acaps/767sec2.pdf, Accessed 5/27/11.

${ }^{18}$ Thomas, R.H., Burley, C.L., and Olson, E.D., "Hybrid Wing Body Aircraft System Noise Assessment With Propulsion Airframe Aeroacoustic Experiments”, AIAA 2010-3913, June, 2010.

${ }_{19}$ Miranda, L.R., Elliott, R.D., and, Baker, W.M., "A Generalized Vortex Lattice Method for Subsonic and Supersonic Flow Applications”, NASA CR 2865, December, 1977. 